\title{
Parental perspectives long term after neonatal clinical trial participation: a survey
}

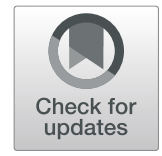

Thomas Salaets $^{1 *}$ D, Emilie Lavrysen ${ }^{1}$, Anne Smits ${ }^{1}$, Sophie Vanhaesebrouck ${ }^{2}$, Maissa Rayyan ${ }^{1}$, Els Ortibus ${ }^{1}$, Jaan Toelen', Laurence Claes $^{3}$ and Karel Allegaert ${ }^{1,4,5}$

\begin{abstract}
Background: Although recruiting newborns is ethically challenging, clinical trials remain essential to improve neonatal care. There is a lack of empirical data on the parental perspectives following participation of their neonate in a clinical trial, especially at long term. The objective of this study is to assess experiences and emotions of parents, long term after trial participation in an interventional drug trial.

Methods: Parents of former participants of five neonatal interventional drug trials were surveyed at long term (313 years ago) after participation. The survey assessed parental contentment with trial participation, perceived influence of the trial on care and health, emotional consequences of participation, and awareness of typical clinical trial characteristics on 6-point Likert scales.

Results: Complete responses were received from 123 parents (52\% of involved families). Twenty percent of parents did not remember participation. Those who remembered participation reported high contentment with overall trial participation (median 5.00), but not with follow-up (median 3.00). Most parents did not perceive any influence of the trial on care (median 2.00) and health (median 2.43). Almost all parents reported satisfaction and pride (median 4.40), while a minority of parents reported anxiety and stress (median 1.44) or guilt (median 1.33) related to trial participation. A relevant minority was unaware of typical trial characteristics (median 4.20; 27\% being unaware).

Conclusions: Overall, parents reported positive experiences and little emotional distress long term after participation. Future efforts to improve the practice of neonatal clinical trials should focus on ensuring effective communication about the concept and characteristics of a clinical trial during consent discussions and on the follow-up after the trial.
\end{abstract}

Keywords: Neonatal clinical trials, Clinical bio-ethics

\section{Background}

Many drugs are still being used off-label in neonates, without adequate evidence [1]. Clinical trials are necessary to identify better care practices, uncover useless or harmful therapies, and reveal new knowledge gaps [2]. Balancing the interests of future patients against the interests of an individual study participant remains a

\footnotetext{
* Correspondence: thomas.salaets@kuleuven.be

'Department of Development and Regeneration, KULeuven, Leuven, Belgium Full list of author information is available at the end of the article
}

difficult ethical exercise [3]. Clinical trial participants are exposed to a treatment of which safety and efficacy are not yet established. To deliver reliable and unbiased information, participants included in a typical clinical trial are randomly and blindly assigned to either a study or control (placebo) group. This concept of a clinical trial does not necessarily serve the individual interests of a study participant.

Clinical research in neonates has specific challenges. Enrollment in trials in the neonatal intensive care unit (NICU) often occurs at a moment when parents are

C C The Author(s). 2020 Open Access This article is licensed under a Creative Commons Attribution 4.0 International License, which permits use, sharing, adaptation, distribution and reproduction in any medium or format, as long as you give appropriate credit to the original author(s) and the source, provide a link to the Creative Commons licence, and indicate if changes were made. The images or other third party material in this article are included in the article's Creative Commons licence, unless indicated otherwise in a credit line to the material. If material is not included in the article's Creative Commons licence and your intended use is not permitted by statutory regulation or exceeds the permitted use, you will need to obtain permission directly from the copyright holder. To view a copy of this licence, visit http://creativecommons.org/licenses/by/4.0/ The Creative Commons Public Domain Dedication waiver (http://creativecommons.org/publicdomain/zero/1.0/) applies to the data made available in this article, unless otherwise stated in a credit line to the data. 
overwhelmed by stress and emotions. The validity of informed consent in this population has therefore been questioned $[4,5]$.

There is a lack of empirical data on how parents evaluate participation in a neonatal drug trial and on how the trial affects their emotional well-being [6]. Currently available studies focused on smaller nonpharmacological experimental interventions and on the parental experience during the trial procedures [7-11]. In the current study, we assessed the perspectives and emotions of parents long term after participation in an interventional drug trial conducted in the NICU. Parental understanding of the trial was assessed and neonatal outcome data collected in order to evaluate possible correlations.

\section{Methods}

Parental perspectives were evaluated through an online questionnaire that was approved by the Ethical Committee of the University Hospitals Leuven. Formal informed consent to participate in this study was asked in the opening question of the questionnaire.

\section{Setting}

All five interventional clinical trials, running in the NICU in University Hospitals Leuven between 2005 and 2015, in which neonates were exposed to a novel treatment (novel product or novel dosing regimen) were selected. The SMOF trial was a double-blinded, randomized controlled clinical trial comparing a new lipid emulsion to a conventional soy emulsion for parenteral nutrition in preterm infants [12]. NIRTURE was a multicenter open-label, randomized controlled trial evaluating the effect of early insulin therapy on mortality and sepsis in very low birth weight infants [13]. The DORIPENEM study was a multicenter phase I clinical trial evaluating the pharmacokinetics, safety, and tolerance of a single dose of intravenous infusion of doripenem in pre (term) neonates [14]. The LAIF-trial was a multicenter double-blinded, placebo-controlled, randomized trial to test the efficacy of adding recombinant bile salt-stimulated lipase to the feeding of preterm infants to promote growth [15]. NEOPROP was a dose-finding study to evaluate the safety and efficacy of different doses of propofol for sedation during semi-elective intubation [16]. The main characteristics of the five included trials can be retrieved from their initial publications, and are summarized in Supplementary Table 1. According to Belgian law, both parents have to sign the study informed consent form. It is furthermore standard practice in our center to discuss participation in a clinical trial with both parents.

\section{Recruitment}

Parents of infants who participated in any of the abovementioned trials were eligible. Families were excluded if they were not familiar with Dutch language or in case of loss of parental authority. Each eligible family received an invitation for an online survey by postal mail, along with two unique access codes (one for each parent). Parents were asked to complete the survey individually. Non-responding families were invited a second time by postal mail and by phone in a third attempt. If hospital records indicated the death of the child, parents were only contacted once. The survey was accessible from October 2017 until March 2018.

\section{Questionnaire}

The items of this questionnaire were developed after reviewing literature and interviewing different stakeholders: neonatologists, psychologists, neonatal research nurses, representatives of the Flemish preemie parent alliance (VVOC [17]), and a subgroup of parents of former study participants $(n=3)$. Face validity of the resulting questionnaire (comprehensibility and completeness) was evaluated by the same stakeholder group.

The survey was formulated in Dutch, and an English translation of the items can be found in Supplementary Tables 2 and 3. A first part aimed to obtain background parental information. Age-adjusted quality of life of the child (or both children if twins) who participated in the trial was assessed by the validated parent-reported PEDsQL scale (Pediatric Quality of Life Inventory) [18]. In the second part, parents were asked whether they remembered participation in the trial. Only respondents who answered "yes" were directed to the third and fourth parts. The third part assessed contentment of parents with different aspects of the trial, whether the trial influenced care for and health of their child and emotional consequences through a set of 52 items. Every item was a statement on which respondents were asked to express their level of agreement on a 6-point Likert scale ranging from one (strong disagreement) to six (strong agreement). Finally, a fourth part inquired awareness on five characteristics of the clinical trial in which they participated. A brief, lay term, explanation of equipoise, the possibility of adverse events, placebo or control groups, blinding, and randomization, was given. Parents indicated if they were aware of these characteristics (one item), and whether knowing this causes any distress (three items). Parents were only directed to the items relevant for the specific trial they participated in.

All items of parts three and four were organized in 17 predefined scales, measuring conceptually comparable experiences or perceptions. Cronbach's $\alpha$ coefficients were calculated to assess the scale reliability [19]. For part three, $\alpha$ 's of all scales ranged from 0.757 to 0.957 , 
while for part four all $\alpha$ 's ranged from 0.639 to 0.908 , indicating overall good reliability (Supplementary Table 2 and 3).

\section{Bayley scales of infant development}

All infants with a gestational age below 32 weeks, born in the University Hospitals Leuven, are invited for neurodevelopmental follow-up, with assessment of Bayley Scales of Infant Development (BSID). Data available for study participants was retrospectively collected. We aimed to use measurements at a prematurity-corrected age of 24 months; however, any assessment was considered if otherwise not available (median 23 months; range 7-36 months). For most infants, BSID-II was used (96\%). The BSID-III motor scale scores were excluded; BSIDIII cognitive and language scale scores were recalculated to BSID-II mental scale scores [20].

\section{Data analysis}

Only complete responses are included in the analysis. All analyses were performed using SPSS (version 25, IBM). Normality was assessed with Shapiro-Wilk-tests. Non-normally distributed variables are described as medians and quartiles, while normally distributed variables are described by means and standard deviations (sd). For parents of twins who both participated in the trial, we only used the lowest value of the PedsQL and BSID-II scale scores of both twins ("worst case scenario"). Construct scale score was calculated by averaging all items of a particular scale. For visual representation, scale values were binned to integers. We interpreted construct scale medians of $1-1.5,1.5-2.5,2.5-3.5,3.5-4.5,4.5-$ 5.5 , and 5.5-6, as respectively very low, low, rather low, rather high, high, and very high levels of the measured construct. Remembrance of trial participation was compared between sexes and trials with a $X^{2}$ test. Scales were compared across sexes and trials using MannWhitney $U$ and Kruskal-Wallis tests, respectively. Spearman's $\rho$ was calculated to study correlations with ordinal or continuous variables such as BSID, PEDsQL, and parental understanding of the trial.

\section{Results}

\section{Respondents}

A total of 194 non-bereaved and 14 bereaved families were eligible for this study. One hundred twenty-three (32\%) non-bereaved (from 103 families; 53\%) and two bereaved parents (from two families) completed the survey (Fig. 1). Respondents were predominantly mothers (71\%), and higher education outside university was the most common educational level. The median time since participation in the trial was 11.5 (range 3.5-13.1) years. All participant characteristics are given in Table 1 .

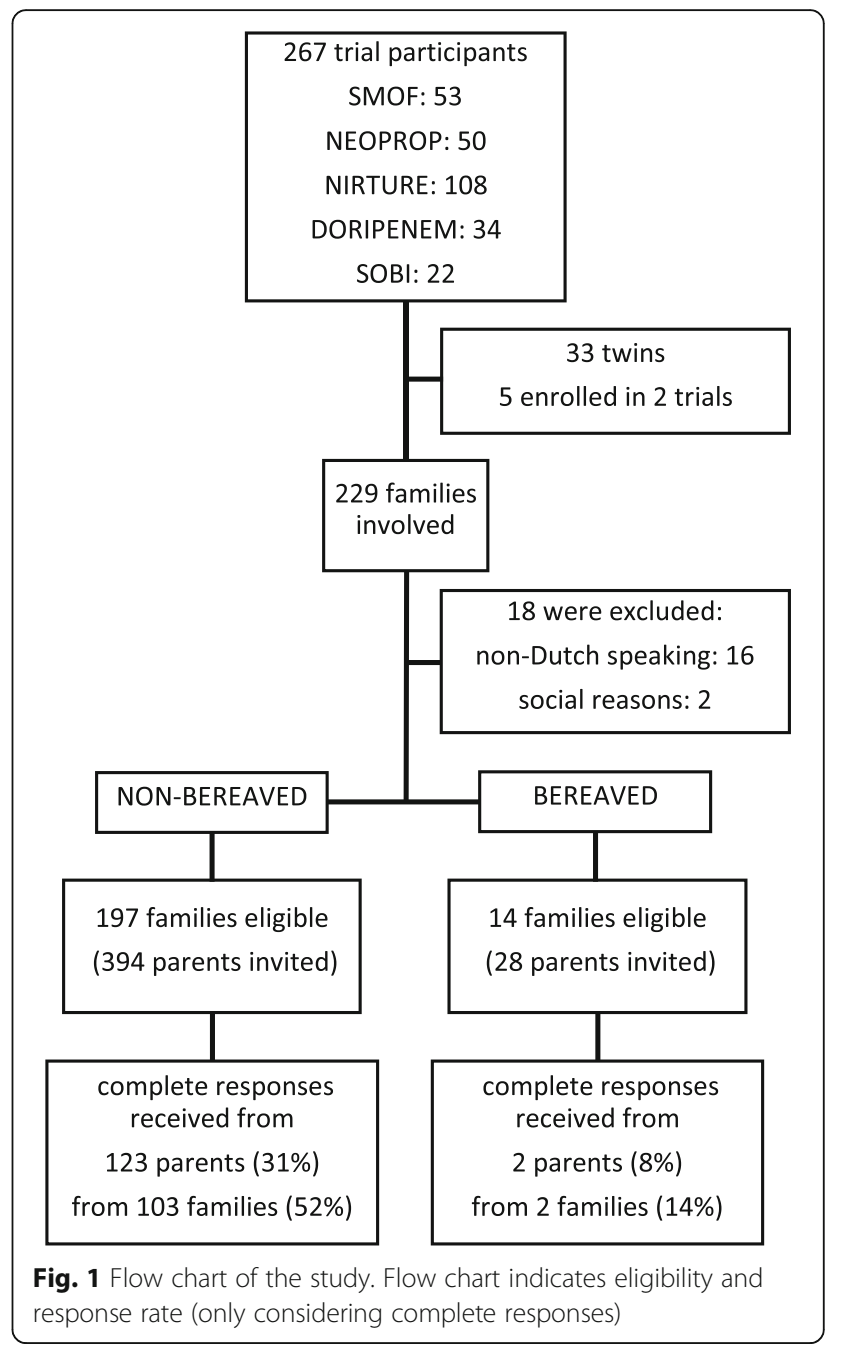

\section{Remembrance of trial participation}

Twenty-five respondents (20\%) did not remember participation of their child in a clinical trial. Remembering trial participation was not significantly correlated to sex, age, parental education, or outcome of the child (Supplementary Table 4). Surprisingly, the longer the time period since participation in the trial, the more respondents remembered participation $(\rho=0.202 ; p=0.025)$. Remembrance was also strongly correlated to the trial $(p=0.016)$, with especially lower remembrance $(61 \%)$ in NEOPROP, the most recent clinical trial (Supplementary Table 5).

\section{Contentment on trial participation}

Overall, parents reported high levels of contentment with trial participation (median score 5.00; Fig. 2). Respondents were also rather happy with the information they received about the trial (median score 4.33); however, $26 \%$ of respondents somehow strongly disagreed. The recruitment and consent procedure of the trial was 
Table 1 Baseline characteristics of survey respondents

\begin{tabular}{|c|c|}
\hline Baseline characteristics per respondent & \\
\hline \multicolumn{2}{|l|}{ Sex, $n(\%)$} \\
\hline Father & $36(29)$ \\
\hline Mother & $87(71)$ \\
\hline Parent of twins, $n(\%)$ & $50(41)$ \\
\hline Parent of twins that were both in trial, $n(\%)$ & $24(20)$ \\
\hline Partner also responded to survey, $n(\%)$ & $20(16)$ \\
\hline $\begin{array}{l}\text { Age at completion of questionnaire, } \\
\text { mean in years }( \pm \text { sd) }\end{array}$ & $41.8( \pm 5.6)$ \\
\hline $\begin{array}{l}\text { Age at participation in study, } \\
\text { median in years (Q1-Q3) }\end{array}$ & $31.7(28.9-34.9)$ \\
\hline $\begin{array}{l}\text { Time since participation in study, } \\
\text { median in years (Q1-Q3) }\end{array}$ & $11.5(5.1-12.2)$ \\
\hline \multicolumn{2}{|l|}{ Trial, $n(\%)$} \\
\hline SMOF & $30(24)$ \\
\hline NIRTURE & $46(37)$ \\
\hline LAIF & $7(6)$ \\
\hline DORIPENEM & $9(7)$ \\
\hline NEOPROP & $31(25)$ \\
\hline \multicolumn{2}{|l|}{ Education, $n(\%)$} \\
\hline Lower secondary education & $11(9)$ \\
\hline Higher secondary education & $31(25)$ \\
\hline Higher education outside university & $44(36)$ \\
\hline Academic education (university degree) & $37(30)$ \\
\hline \multicolumn{2}{|l|}{ BSID-II, mean $( \pm \mathrm{sd})^{\mathrm{a}}$} \\
\hline Mental index & $99.0( \pm 18.5)$ \\
\hline Motor index & $95.8( \pm 19.8)$ \\
\hline Total PedsQL, median (Q1-Q3) ${ }^{\mathrm{a}}$ & $81.7(73.3-91.7)$ \\
\hline
\end{tabular}

overall positively evaluated (median score 4.58). In contrast, the majority of parents (63\%) was rather unsatisfied with the follow-up after the trial (median score 3.00). There were no significant correlations between contentment and sex, education, time since trial participation, trial, BSID-II, and PedsQL (Supplementary Table 6).

\section{Perceived influence of the trial on care and health}

None of the respondents thought that trial participation affected the routine care for their child (median score 2.00; Fig. 2). Only one respondent thought that participation influenced the health of his child (median score 2.43). Thirty-four percent of respondents somewhat strongly agreed that the trial was beneficial for their child (median score 3.00), while no respondents thought it was negative (median score 1.75). Parent-reported quality of life of the child was negatively correlated to the perception that participation in the trial influenced care $(p=0.021)$, and tended to be negatively correlated to the perception that it influenced health $(p=0.059$; Supplementary Table 6). Furthermore, the perception that participation had a positive influence on care and health was more common in participants with a lower educational attainment $(p=0.042)$ and in parents of infants with lower BSID-II mental scale scores $(p=0.031)$.

\section{Emotional consequences of trial participation}

Rather high levels of satisfaction and pride were reported (median score 4.40; Fig. 2). Parents reported very low levels of anxiety and distress (median score 1.44) and guilt (median score 1.33). Parental education was negatively correlated to satisfaction and pride and positively correlated to guilt (respectively, $p=0.007$ and $p=0.016$; Supplementary Table 6).

\section{Awareness of typical trial characteristics}

Most, but not all, parents were aware of the characteristics of the clinical trial in which their child participated (median score 4.20; 27\% being unaware; Fig. 3). Looking at individual characteristics, awareness was lowest for the possibility of adverse events, followed by equipoise, randomization, the presence of a control group, and blinding. For all five trial characteristics, a large majority of respondents did not feel distressed after reading a brief explanation on the topic (medians ranging from 2 to 2.33). There was a strong negative correlation between awareness and distress for each individual characteristic ( $p \leq 0.001$; Supplementary Table 7).

Fathers were overall more aware $(p=0.008-0.178)$ and less distressed $(p=0.008-0.128)$ than mothers about the characteristics of the trial (Supplementary Table 8). Overall, awareness about typical trial characteristics tended to be related to the trial in which the respondent's child participated $(p=0.0665)$. Being aware about the characteristics of the trial was also positively correlated with positive perspectives on trial participation, and negatively to anxiety and guilt (Supplementary Table 9).

\section{Bereaved parents}

Only two bereaved parents responded, resulting in insufficient data for this group.

\section{Discussion}

Overall, parents who remembered the trial looked back at the participation of their child as a positive experience. They were overall contented with their participation and reported rather high levels of satisfaction and pride and low levels of anxiety, stress, and guilt. These findings could provide comfort to researchers, who often 


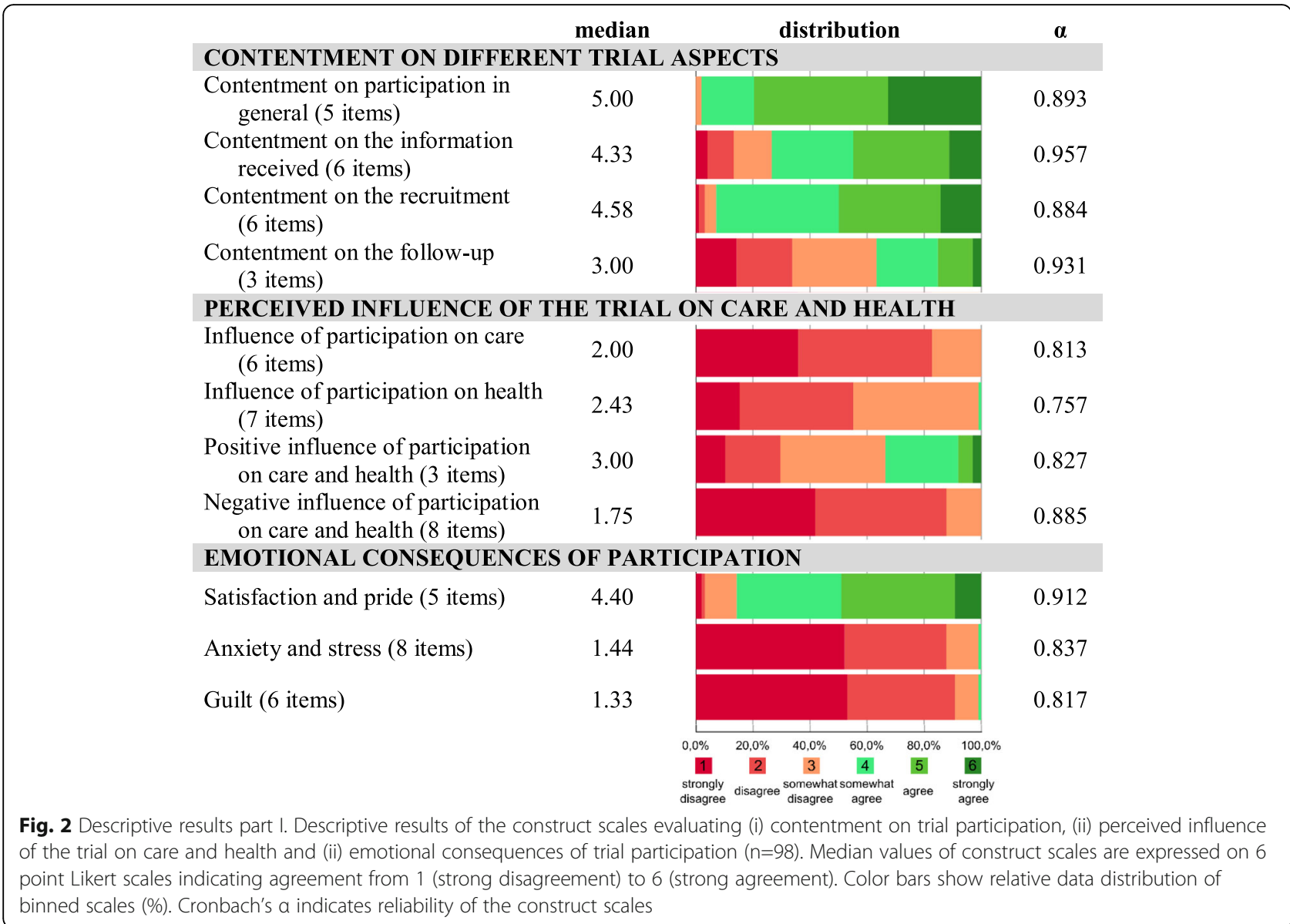

doubt whether it is acceptable to burden the already distressed family of a sick newborn with recruitment for a clinical trial [21]. Furthermore, it is reassuring that parents of babies with worse outcome are equally comfortable with trial participation. Other studies have previously documented comparable positive experiences among parents of neonatal clinical trial perspectives [7$9,11]$. The current study however is the first to evaluate the perspectives of parents of neonates participating in interventional pharmacological trials, with a relatively invasive experimental intervention, and once the longterm outcome is known.

Interestingly, $20 \%$ of the responding parents did not remember trial participation. We observed significant differences between parents participating in the five included trials. More parents forgot participation in NIRTURE (22\%) and NEOPROP (39\%) in comparison to the other 3 trials. Both NIRTURE and NEOPROP required recruitment very early after birth, in often instable preterm babies. Additionally, NEOPROP involved only a very brief investigational drug exposure, and follow-up was limited at $12 \mathrm{~h}$. We hypothesize that emotional distress at the time of consent and during the study procedure negatively affects remembrance of trial participation.
It has often been questioned whether emotionally distressed parents of sick newborns are able to give voluntary, competent, and informed consent for trial participation [4, 21-24]. Overall, good levels of awareness on the characteristics of the clinical trial in which their child participated indicate that most parents in this study (regardless of education) understood to what they consented. These results are comparable to earlier studies with parents of pediatric study participants, [25] but contrast qualitative work demonstrating poor understanding of the concept of a clinical trial and randomization in a sample of parents of neonatal study participants [26]. In our sample, fathers were significantly more aware and less distressed about typical trial characteristics. We hypothesize that mothers are more emotionally distressed at the moment of consent and often still bear the consequences from medical conditions leading to preterm birth that also affect cognitive functioning and possibly memory $[27,28]$.

Nevertheless, still, $35 \%$ and $46 \%$ of the respondents were unaware of the uncertainty concerning the effectivity (equipoise) and safety (possible adverse events) of the experimental intervention. Furthermore, 34\% of respondents perceived positive effects of the clinical trial, while 


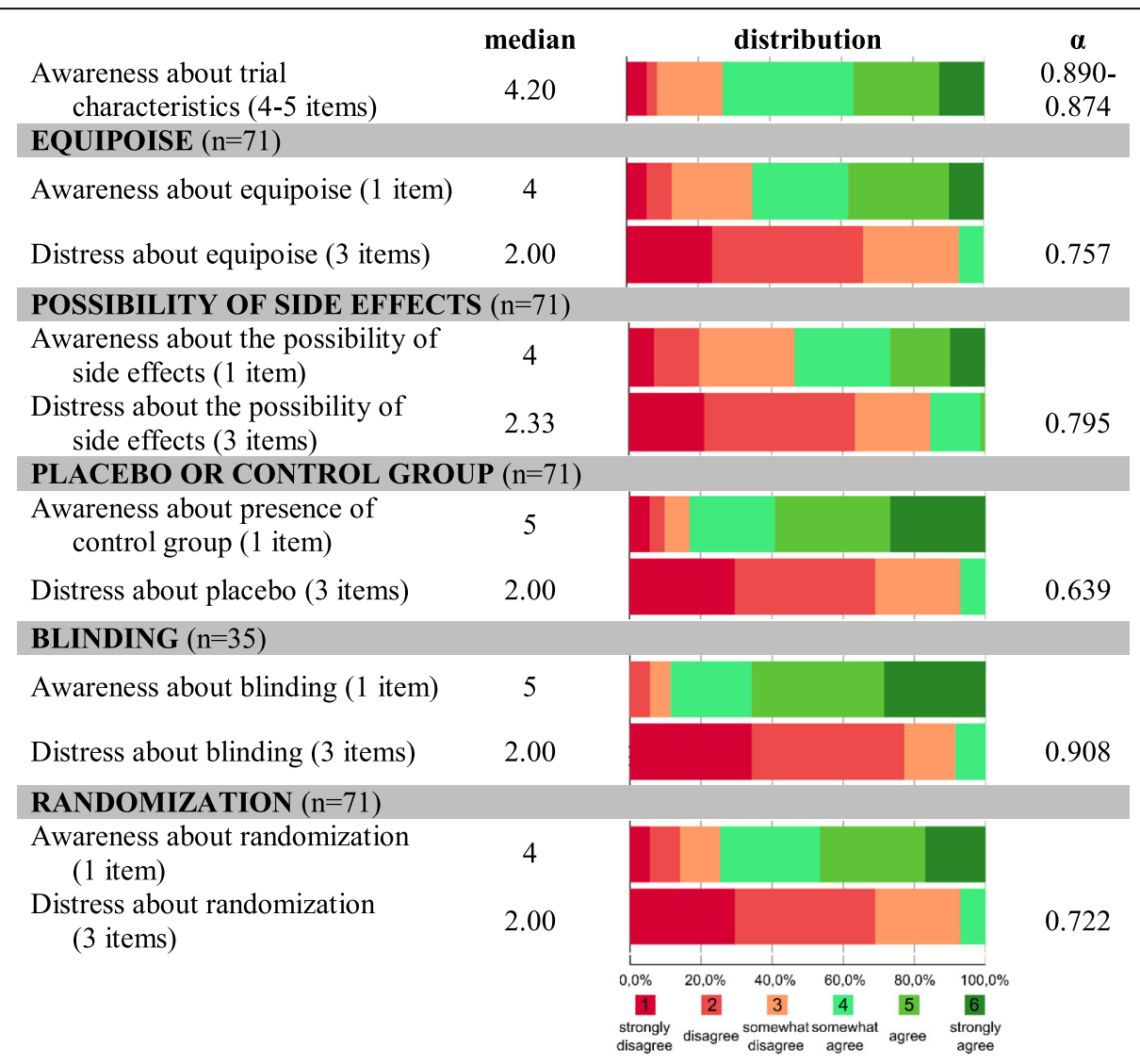

Fig. 3 Descriptive results part II. Descriptive results of the construct scales and items evaluating awareness of and distress about typical clinical trial characteristics $(n=35-71)$. Median values of construct scales are expressed on 6 point Likert scales indicating agreement from 1 (strong disagreement) to 6 (strong agreement). Color bars show relative data distribution of binned scales (\%). Cronbach's a indicates reliability of the construct scales

no respondents perceived negative effects. The disproportional optimism regarding the beneficial effects of trial participation due to a failure in discriminating the goals of a trial from normal clinical care is called therapeutic misconception $[29,30]$. Our data suggests that parents with a lower educational attainment are more likely to overestimate the beneficial effects of the trial and underestimate the side effects.

Self-reported awareness of study characteristics was in our study strongly correlated to positive perspectives on trial participation. Researchers asking for consent should ensure that parents capture and retain the concept of the trial properly. Recently, professional stakeholders and parent representatives made recommendations to ensure effective communication in consent procedures in this setting [31]. Alternatively, other types of consent procedures avoiding recruitment during a stressful period (such as antenatal consent or deferred consent) could be explored [4, 32].

This study has some limitations. First, one has to be careful in generalizing our findings. It is possible that our study is biased by selection of parents at least remembering trial participation, or having a strong opinion on it. Our results on remembrance of the trial and awareness of different trial characteristics indicate that the perspectives of parents might also be different depending on incidental aspects of the specific trial. We also noted important differences between trials on remembrance of participation. Extrapolation to trials with other specific characteristics might be difficult. Second, it is possible that some results are biased by social desirability, leading to a favorable trial evaluation. A qualitative study would be able to explore how important this aspect was, and whether parents had truly in-depth understanding of the concept and risks of the trial in which they participated $[26,33]$. Third, despite our focus on long-term perspectives, the long recall time (median 11.5 years) might have made it difficult to give a thought out opinion on some of the questions in the survey. Finally, with an adapted and less aggressive recruitment strategy, we were only able to recruit two bereaved parents. For the perspectives of this group, we can refer to the BRACELET study that has shown that most bereaved parents consider the trial as irrelevant to their child's death [34]. 


\section{Conclusions}

In conclusion, parents report positive perspectives and low levels of emotional distress at long term after trial participation of their neonate. This finding can reassure clinicians, researchers, and review boards who worry about the emotional effect of trial participation on parents of neonates. Future efforts to improve the practices of neonatal clinical trials should focus on ensuring effective communication of the concept, risks, and benefits of the trial to already distressed parents. Special attention should go to mothers early after birth (that were often less aware of study characteristics) and parents with lower educational attainment (at risk of therapeutic misconception).

\section{Supplementary information}

Supplementary information accompanies this paper at https://doi.org/10. 1186/s13063-020-04787-0.

Additional file 1: Supplementary Tables 1-9

\section{Abbreviations}

NICU: Neonatal intensive care unit; WOC: Vlaamse Vereniging van Ouders van Couveusekinderen (Flemish preemie parent alliance); PEDsQL: Pediatric Quality of Life Inventory; BSID: Bayley Scale of Infant Development

\section{Acknowledgements}

We acknowledge WOC and all parents and partners involved in the exploratory interviews leading to the development of the survey. Furthermore, we thank all parents that were willing to participate in the survey.

\section{Authors' contributions}

TS designed and performed the study and coordinated the manuscript writing. EL was involved in data collection (surveying) and analysis. AS, SV, and MR provided data from their former study participants and provided advice on every step of the study. EO provided and helped with the analysis of the BSID data. LC supervised the design of the survey instrument and guided the statistical analysis. KA and JT guided the design and proceeding of the study and supervised manuscript writing. All authors were involved in drafting and critically revising the manuscript. All authors approved the final manuscript as submitted and agree to be accountable for all aspects of the work.

\section{Funding}

This work was performed in the context of the SafePedrug project (a project supported by an IWT grant (SBO 130033)). IWT did not have any role in the design, performance, or interpretation of the study.

\section{Availability of data and materials}

The anonymized dataset used and/or analyzed during the current study is available from the corresponding author on reasonable request.

\section{Ethics approval and consent to participate}

The study was approved by the Ethical Committee of the University Hospitals Leuven under the number s60033. The first question of the survey asked for consent of participants, a separate question asked for consent to use the BSID-data of their child.

\section{Consent for publication}

Not applicable.

\section{Competing interests}

The authors declare that they have no conflicts of interest to disclose.

\section{Author details}

${ }^{1}$ Department of Development and Regeneration, KULeuven, Leuven, Belgium. ${ }^{2}$ Department of Internal Medicine and Pediatrics, UGent, Ghent, Belgium. ${ }^{3}$ Faculty of Psychology and Educational Studies, Unit of Clinical Psychology, KULeuven, Leuven, Belgium. ${ }^{4}$ Department of Pharmaceutical and Pharmacological Sciences, KULeuven, Leuven, Belgium. ${ }^{5}$ Department of Hospital Pharmacy, Erasmus MC, Rotterdam, The Netherlands.

Received: 1 May 2020 Accepted: 5 October 2020

Published online: 02 November 2020

\section{References}

1. Stiers $\mathrm{J}$, Ward RM. Newborns, one of the last therapeutic orphans to be adopted. JAMA Pediatr. 2014;168:106-8.

2. DeMauro SB, Foglia EE, Schmidt B. The ethics of neonatal research: a trialists' perspective. Semin Fetal Neonatal Med. 2015;20(6):431-5.

3. Allmark P, Mason S, Gill AB, Megone $C$. Is it in a neonate's best interest to enter a randomised controlled trial? J Med Ethics. 2001;27(2):110-3.

4. McKechnie L, Gill AB. Consent for neonatal research. Arch Dis Child Fetal Neonatal Ed. 2006:91(5):F374-6.

5. Ballard HO, Shook LA, Desai NS, Anand KJ. Neonatal research and the validity of informed consent obtained in the perinatal period. J Perinatol. 2004;24(7):409-15

6. Janvier A, Farlow B. The ethics of neonatal research: an ethicist's and a parents' perspective. Semin Fetal Neonatal Med. 2015;20(6):436-41.

7. Stenson BJ, Becher JC, McIntosh N. Neonatal research: the parental perspective. Arch Dis Child Fetal Neonatal Ed. 2004;89(4):F321-3.

8. Harris DL, Weston PJ, Harding JE. Mothers of babies enrolled in a randomized trial immediately after birth report a positive experience. J Perinatol. 2014:34(4):280-3.

9. Ayers S, Sawyer A, During C, Rabe H. Parents report positive experiences about enrolling babies in a cord-related clinical trial before birth. Acta Paediatr. 2015;104(4):e164-70.

10. Bradshaw L, Sawyer A, Mitchell E, Armstrong-Buisseret L, Ayers S, Duley L. Women's experiences of participating in a randomised trial comparing alternative policies for timing of cord clamping at very preterm birth: a questionnaire study. Trials. 2019:20(1):225.

11. Cumberpatch AR, Weston PJ, Harding JE, Harris DL. Parents of babies who participated in an invasive clinical study report a positive experience: the Glucose in Well Babies (GLOW) study. Arch Dis Child Fetal Neonatal Ed. 2020;105(1):4-7.

12. Rayyan M, Devlieger H, Jochum F, Allegaert K. Short-term use of parenteral nutrition with a lipid emulsion containing a mixture of soybean oil, olive oil, medium-chain triglycerides, and fish oil: a randomized double-blind study in preterm infants. JPEN J Parenter Enteral Nutr. 2012;36(1 Suppl):81s-94s.

13. Beardsall K, Vanhaesebrouck S, Ogilvy-Stuart AL, Vanhole C, Palmer CR, van Weissenbruch $M$, et al. Early insulin therapy in very-low-birth-weight infants. N Engl J Med. 2008:359(18):1873-84.

14. Cirillo I, Vaccaro N, Castaneda-Ruiz B, Redman R, Cossey V, Bradley JS, et al. Open-label study to evaluate the single-dose pharmacokinetics, safety, and tolerability of doripenem in infants less than 12 weeks in chronological age. Antimicrob Agents Chemother. 2015;59(8):4742-9.

15. Casper C, Hascoet JM, Ertl T, Gadzinowski JS, Carnielli V, Rigo J, et al. Recombinant bile salt-stimulated lipase in preterm infant feeding: a randomized phase 3 study. PLoS One. 2016;11(5):e0156071.

16. Smits A, Thewissen L, Caicedo A, Naulaers G, Allegaert K. Propofol dosefinding to reach optimal effect for (semi-)elective intubation in neonates. J Pediatr. 2016;179:54-60 e9.

17. WOC.be - Vlaamse Vereniging voor Ouders van Couveusekinderen. 2020 [Available from: https://www.vvoc.be/. Accessed 16 September 2020.

18. Varni JW, Seid M, Kurtin PS. PedsQL 4.0: reliability and validity of the Pediatric Quality of Life Inventory version 4.0 generic core scales in healthy and patient populations. Med Care. 2001;39(8):800-12.

19. JCN. Assessment of reliability. Psychometric theory. 2nd edition ed. New York: McGraw-Hill; 1978.

20. Moore T, Johnson S, Haider S, Hennessy E, Marlow N. Relationship between test scores using the second and third editions of the Bayley scales in extremely preterm children. J Pediatr. 2012;160(4):553-8.

21. Shilling V, Williamson PR, Hickey H, Sowden E, Smyth RL, Young B. Processes in recruitment to randomised controlled trials of medicines for children (RECRUIT): a qualitative study. Health Technol Assess. 2011;15(15):1-116. 
22. Burgess E, Singhal N, Amin H, McMillan DD, Devrome H. Consent for clinical research in the neonatal intensive care unit: a retrospective survey and a prospective study. Arch Dis Child Fetal Neonatal Ed. 2003;88(4):F280-5 discussion F5-6.

23. Wilman E, Megone C, Oliver S, Duley L, Gyte G, Wright JM. The ethical issues regarding consent to clinical trials with pre-term or sick neonates: a systematic review (framework synthesis) of the empirical research. Trials. 2015;16:502.

24. Mason SA, Allmark PJ. Obtaining informed consent to neonatal randomised controlled trials: interviews with parents and clinicians in the Euricon study. Lancet. 2000;356(9247):2045-51.

25. Chappuy H, Doz F, Blanche S, Gentet JC, Pons G, Treluyer JM. Parental consent in paediatric clinical research. Arch Dis Child. 2006;91(2):112-6.

26. Snowdon C, Garcia J, Elbourne D. Making sense of randomization; responses of parents of critically ill babies to random allocation of treatment in a clinical trial. Soc Sci Med. 1997;45(9):1337-55.

27. Ionio C, Colombo C, Brazzoduro V, Mascheroni E, Confalonieri E, Castoldi F, et al. Mothers and fathers in NICU: the impact of preterm birth on parental distress. Eur J Psychol. 2016;12(4):604-21.

28. Kurosaki H, Nakahata K, Donishi T, Shiro M, Ino K, Terada M, et al. Effects of perinatal blood pressure on maternal brain functional connectivity. PLoS One. 2018;13(8):e0203067.

29. McConville P. Presuming patient autonomy in the face of therapeutic misconception. Bioethics. 2017:31(9):711-5.

30. Woods S, Hagger LE, McCormack P. Therapeutic misconception: hope, trust and misconception in paediatric research. Health Care Anal. 2014;22(1):3-21.

31. Neyro V, Elie V, Thiele N, Jacqz-Aigrain E. Clinical trials in neonates: how to optimise informed consent and decision making? A European Delphi survey of parent representatives and clinicians. PLoS One. 2018;13(6):e0198097.

32. McCarthy KN, Ryan NC, O'Shea DT, Doran K, Greene R, Livingstone V, et al. Parental opinion of consent in neonatal research. Arch Dis Child Fetal Neonatal Ed. 2019;104(4):F409-f14.

33. Harvey M, Nongena P, Edwards D, Redshaw M. 'We knew it was a totally at random thing': parents' experiences of being part of a neonatal trial. Trials. 2017;18(1):361

34. Snowdon C, Brocklehurst P, Tasker R, Ward Platt M, Harvey S, Elbourne D. Death, bereavement and randomised controlled trials (BRACELET): a methodological study of policy and practice in neonatal and paediatric intensive care trials. Health Technol Assess. 2014:18(42):1-410.

\section{Publisher's Note}

Springer Nature remains neutral with regard to jurisdictional claims in published maps and institutional affiliations.

Ready to submit your research? Choose BMC and benefit from:

- fast, convenient online submission

- thorough peer review by experienced researchers in your field

- rapid publication on acceptance

- support for research data, including large and complex data types

- gold Open Access which fosters wider collaboration and increased citations

- maximum visibility for your research: over $100 \mathrm{M}$ website views per year

At $\mathrm{BMC}$, research is always in progress.

Learn more biomedcentral.com/submissions 